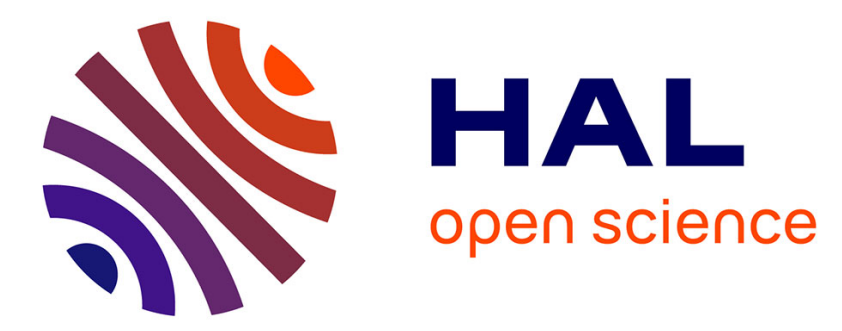

\title{
Kinetic study of forest fuels by TGA: Model free kinetic approach for the prediction of phenomena
}

Valérie Leroy, Dominique Cancellieri, Eric Leoni, Jean Louis Rossi

\section{To cite this version:}

Valérie Leroy, Dominique Cancellieri, Eric Leoni, Jean Louis Rossi. Kinetic study of forest fuels by TGA: Model free kinetic approach for the prediction of phenomena. Thermochimica Acta, 2010, 497, pp.1-6. 10.1016/j.tca.2009.08.001 . hal-00547599

\section{HAL Id: hal-00547599 \\ https://hal.science/hal-00547599}

Submitted on 16 Dec 2010

HAL is a multi-disciplinary open access archive for the deposit and dissemination of scientific research documents, whether they are published or not. The documents may come from teaching and research institutions in France or abroad, or from public or private research centers.
L'archive ouverte pluridisciplinaire HAL, est destinée au dépôt et à la diffusion de documents scientifiques de niveau recherche, publiés ou non, émanant des établissements d'enseignement et de recherche français ou étrangers, des laboratoires publics ou privés. 


\title{
Kinetic study of forest fuels by TGA: Model-free kinetic approach for the prediction of phenomena
}

\author{
Valérie Leroy $^{\mathrm{a}, 1}$, Dominique Cancellieri ${ }^{\mathrm{b}, 2}{ }^{\text {, Eric Leoni }}{ }^{\mathrm{b}, *}{ }^{\text {, Jean-Louis Rossi }}{ }^{\mathrm{b}, 2}$ \\ a ICARE-CNRS UPR 3021, 1c, avenue de la recherché scientifique, 45071 Orléans, France \\ b SPE-CNRS UMR 6134, Campus Grimaldi B.P 52, 20250 Corte, France
}

\section{A R T I C L E I N F O}

\section{Article history:}

Received 27 March 2009

Received in revised form 3 August 2009

Accepted 4 August 2009

Available online 13 August 2009

\section{Keywords:}

Model-free kinetic

Thermal degradation

Oxidation

Forest fuels

\begin{abstract}
A B S T R A C T
The kinetics of thermal decomposition of a forest fuel was studied by thermogravimetry. Experiments were monitored under air and non-isothermal conditions from 400 to $900 \mathrm{~K}$. We used a classical modelfree method, the Kissinger-Akahira-Sunose (KAS) method to calculate the activation energy vs. the conversion degree of the reaction on the whole temperature domain. Analyses were performed at 10, 20 and $30 \mathrm{~K} / \mathrm{min}$. As expected, the complex structure of lignocellulosic fuels involved several steps with different energies in the degradation processes. The algorithm developed here, allows the calculation and the simulation of the solid temperature at different conversion degree for various heating rates. The good correlation between experiments and simulations validated the proposed algorithm. Then, kinetics parameters were used to perform simulations up to heating rates outside the functioning range of the thermal analyser.
\end{abstract}

(C) 2009 Elsevier B.V. All rights reserved.

\section{Introduction}

Thermal decomposition kinetics of biomass is an important key in thermochemical conversion processes aimed at the production of energy and chemical products [1-3]. Biomass is also implicated in wildland fire. Indeed, the rate of mass loss due to thermal decomposition determines the available volatile fuel in the flaming zone. To a lesser extent, the mass loss rate also determines the heat release rate (product of the heat of combustion and the mass of fuel burned). Therefore, the analysis of the thermal degradation of plant fuels is decisive for wildland fire modelling and fuel hazard studies [4-10]. Numerous studies led to different degradation schemes in inert [11-13] environment but only a few were monitored in air atmosphere [14-16]. We propose here to study the thermal degradation of a forest fuel under air with thermogravimetry and kinetics analysis on the data. Degradation of lignocellulosic biomass is a very complex process of interdependent reactions; nevertheless it can be reduced to the reaction illustrated in Fig. 1.

Between 373 and $553 \mathrm{~K}$ only non-combustible gases are produced, primarily water vapour with some carbon monoxide and traces of formic and acetic acids [17]. From 553 to $773 \mathrm{~K}$ active pyrolysis takes place. Pyrolysis breaks down the substance molecules into low molecular mass gases (volatiles), highly

\footnotetext{
* Corresponding author. Tel.: +33 495450139.

E-mail address: eleoni@univ-corse.fr (E. Leoni).

1 Tel.: +33238255499.

2 Tel.: +33495450139.
}

flammable tars and carbonaceous char. The whole process is complex and lead to solid degradation and gaseous reactions. Thermogravimetric analyses were focused on solid phase degradation. In solid-state, a variation in apparent activation energy could be observed for an elementary reaction due to the heterogeneous nature of the solid or due to a complex reaction mechanism. This variation can be detected by isoconversional or model-free methods [18]. The isoconversional analysis provides a fortunate compromise between the oversimplified but widely used singlestep Arrhenius kinetic treatment and the prevalent occurrence of processes whose kinetics are multi-step and/or non-Arrhenius [19]. These methods allow estimates of the apparent activation energy at progressive degrees of conversion for an independent model. These data are obtained by conducting multiple experiments at different heating rates. Application of model-free methods was highly recommended in order to obtain a reliable kinetic description of the investigated process. In a previous work we demonstrate the utility of thermal analysis in forest fuel hazard study [20], here we propose a kinetic study based on an isoconversional method and a simulation of the solid temperature in conditions outside the experimental range of thermal analysis.

\section{Experimental}

\subsection{Sampling}

We sampled the foliage and aerial parts of Arbutus Unedo (Strawberry tree). This is an abundant species in the Corsican vegetation concerned by wildland fires. Plant materials were collected from a 


\begin{tabular}{|ll|}
\hline \multicolumn{2}{|l|}{ Nomenclature } \\
$\alpha$ & conversion degree \\
$m$ & mass of the sample $(\mathrm{mg})$ \\
$m_{0}$ & initial sample mass $(\mathrm{mg})$ \\
$m_{\infty}$ & final sample mass $(\mathrm{mg})$ \\
$T$ & temperature $(\mathrm{K})$ \\
$t$ & time (min) \\
$f(\alpha)$ & kinetic model reaction \\
$g(\alpha)$ & integral form of the $\mathrm{kinetic}$ model reaction \\
$p(x)$ & exponential integral \\
$A$ & pre-exponential factor $(1 / \mathrm{s})$ \\
$E_{a}$ & activation energy $(\mathrm{kJ} / \mathrm{mol})$ \\
$R$ & gas constant $=8.314 \mathrm{~J} / \mathrm{mol} / \mathrm{K}$ \\
$\beta$ & heating rate $(\mathrm{K} / \mathrm{min})$ \\
$W$ & product log function \\
\hline
\end{tabular}

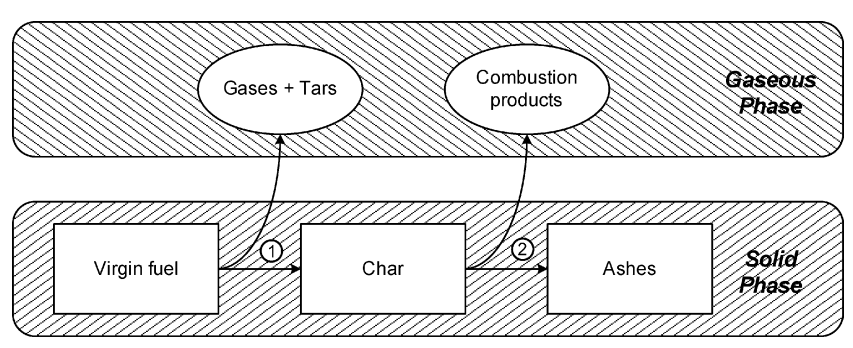

(1) Pyrolysis step (2) Smoldering combustion step

Fig. 1. Degradation of biomass.

natural Mediterranean ecosystem situated away from urban areas in order to prevent any pollution on the samples. A bulk sample from six individual plants was collected in order to minimize interspecies differences. About $500 \mathrm{~g}$ of plant were brought to the laboratory, washed with deionized water and oven-dried for $12 \mathrm{~h}$ at $333 \mathrm{~K}$ [21]. Only small particles $(<6 \mathrm{~mm})$ are considered in governing the dynamic of fire spread [22-24]. Dry samples were then grounded and sieved to pass through a $600 \mu \mathrm{m}$ mesh, then kept to the desiccator. The sieved powdery sample was stored in airtight plastic containers for future use. Thermal analyses were performed on these powders. The moisture content coming from self-rehydration was about $4 \%$ for all the samples before the analysis. The elemental analysis carried out at the SCA USR59 CNRS gave the following composition in carbon, hydrogen, oxygen, and mineral matters: $48.3 \% / 6.2 \% / 40.3 \% / 5.2 \%$.

\subsection{Thermogravimetric experiments}

TGA dynamic experiments were performed using a PerkinElmer TGA Pyris 1. Temperature, furnace and weight of the TGA were calibrated according to the manufacturer's recommendation by measuring Curie point of magnetic standards: perkalloy ${ }^{\circledR}$ and alumel. The pulverized samples were conditioned in $33 \mu \mathrm{L}$ open platinium crucibles with $10.000 \pm 0.005 \mathrm{mg}$. The furnace was continuously purged with a flowing atmosphere of air at a fixed metered flow rate $50 \mathrm{~mL} / \mathrm{min}$ to sweep the evolved gases from the reaction zone, thereby reducing the extent of secondary reactions such as thermal cracking, repolymerisation and recondensation. Experiments were performed at different heating rates $(\beta=10-40 \mathrm{~K} / \mathrm{min}$ ) from room temperature to $900 \mathrm{~K}$ and the uniformity of the sample was maintained by spreading it uniformly over the crucible base in all the experiments. The sample temperature, which is controlled by a thermocouple, did not exhibit any systematic deviation from preset linear temperature programs. All experiments were performed three times.

\section{Kinetic procedure}

\subsection{Model-free kinetic MFK algorithm}

As we used TGA records the conversion degree is defined as:

$\alpha=\frac{m_{0}-m}{m_{0}-m_{\infty}}$

The rate of heterogeneous solid-state reactions can generally be described by:

$\frac{d \alpha}{d t}=A \mathrm{e}^{-E_{a} / R T} f(\alpha)$

The temperature dependence of the rate constant is described by the Arrhenius equation. Galwey and Brown [25] presented a theoretical justification for the application of the Arrhenius equation to the kinetics of solid-state reactions, and it has now been recognized that this empirical equation can represent the experimental rate data as function of temperature accurately for both homogeneous and heterogeneous reactions [26]. Some papers have demonstrated how a complete isoconversional kinetic analysis can be performed using the dependence of the activation energy, in association with thermo-analytical data [27-29].

The parameters of the reaction kinetics were determined using the following procedure: under non-isothermal conditions in which a sample is heated at a constant rate, the explicit temporal dependence in Eq. (2) is eliminated through the following trivial transformation.

$\frac{d \alpha}{d T}=\frac{A}{\beta} \mathrm{e}^{-E_{a} / R T} f(\alpha)$

$g(\alpha)=\int_{0}^{\alpha} \frac{d \alpha}{f(\alpha)}=\frac{A}{\beta} \int_{T_{0}}^{T} \mathrm{e}^{-E_{a} / R T} d T=\frac{A E_{a}}{R \beta} p(x)$

with $x=E_{a} / R T$ and $p(x)=\int_{x_{0}}^{\infty} \mathrm{e}^{-x} / x^{2} d x$.

Kinetics analyses are traditionally expected to produce an adequate kinetic description of the process in terms of the reaction model and the Arrhenius parameters. There are many methods for analysing solid-state kinetic data. These methods may be classified according to the experimental conditions selected and the mathematical analysis performed. Experimentally, either isothermal or non-isothermal methods are employed. The earliest kinetics studies were performed under isothermal conditions [29] but a major problem is that a typical solid-state process has its maximum reaction rate at the beginning of the transformation. However, the advantages of the non-thermal experimental technique are at least partially compensated by serious computational difficulties associated with the kinetic analysis [30].

Several mathematical methods can be used to calculate the kinetic of solid-state reactions: model-fitting and isoconversional (model-free) methods. A model-fitting method involves two fits: the first establishes the model that best fits data while the second determines specific kinetic parameters such as activation energy and pre-exponential factor using Arrhenius equation. The modelfitting approach has the advantage that only one TGA measurement is needed. However, almost any $f(\alpha)$ can satisfactorily fit the data by virtue of the Arrhenius parameters compensation effects and only a single pair of Arrhenius parameters results from the model-fitting method. Consequently, researchers give up this kind of method for the benefit of isoconvertional methods, which can compute kinetic parameters without modelling assumptions [31,32]. The isoconversional method has the ability to reveal complexity of the process in the form of a functional dependence of the activation energy $E_{a}$ on the extent of conversion $\alpha$. The basic assumption of these methods is that the reaction rate for a constant extent of conversion, $\alpha$, depends only on the temperature $[33,34]$. To use these methods, 
Table 1

Linear regression equation according to conversion degree by application of KAS method for Arbutus Unedo.

\begin{tabular}{lll}
\hline$\alpha$ & $y=a x+b^{\mathrm{a}}$ & $r^{2}$ \\
\hline 0.05 & $y=-7587.6 x+10.119$ & 0.9986 \\
0.10 & $y=-7700.8 x+10.236$ & 0.9999 \\
0.15 & $y=-8788.9 x+11.442$ & 0.9998 \\
0.20 & $y=-9449 x+11.999$ & 0.9986 \\
0.25 & $y=-10169 x+12.774$ & 1 \\
0.30 & $y=-10709 x+13.254$ & 0.9995 \\
0.35 & $y=-10577 x+12.553$ & 0.9948 \\
0.40 & $y=-10709 x+12.349$ & 0.9939 \\
0.45 & $y=-10199 x+11.073$ & 0.9915 \\
0.50 & $y=-9781.2 x+9.9597$ & 0.9858 \\
0.55 & $y=-8782.7 x+7.8668$ & 0.9801 \\
0.60 & $y=-7824.7 x+5.8464$ & 0.9806 \\
0.65 & $y=-6741.2 x+3.7126$ & 0.9789 \\
0.70 & $y=-5940.2 x+2.1753$ & 0.9935 \\
0.75 & $y=-5132.2 x+0.7982$ & 0.9975 \\
0.80 & $y=-4368.2 x-0.4271$ & 0.9990 \\
0.85 & $y=-3777.5 x-1.3623$ & 0.9994 \\
0.90 & $y=-3265.5 x-2.1571$ & 0.9999 \\
0.95 & $y=-3194.1 x+2.0836$ & 0.9999 \\
\hline
\end{tabular}

a $a=E_{a \alpha} / R, b=\left[\ln \left(A_{\alpha k} R / E_{a \alpha}\right)-\ln g\left(\alpha_{k}\right)\right]$ and $x=1 / T_{j k}$.

a series of experiments has to be performed at different heating rates $[34,35]$. The knowledge of $E_{a}$ vs. $\alpha$ allows detecting multistep processes and predicting the reaction "kinetics scheme" [27] over a wide temperature range. Several methods do exist [35-37], for this work we chose the method of Kissinger-Akahira-Sunose (KAS) [37] applied without any assumption concerning the kinetic model. The Kissinger-Akahira-Sunose method uses the approximation presented in Eq. (5):

$p(x) \approx \frac{e^{-x}}{x^{2}}$

Taking into account the approximation, the logarithm of Eq. (4) gives:

$\ln \left(\frac{\beta_{j}}{T_{j k}^{2}}\right)=\left[\ln \left(\frac{A_{\left(\alpha_{k}\right)} R}{E_{a}\left(\alpha_{k}\right)}\right)-\ln g\left(\alpha_{k}\right)\right]-\frac{E_{a}\left(\alpha_{k}\right)}{R T_{j k}}$

where $E_{a \alpha}$ and $A_{\alpha}$ are respectively the apparent activation energy and the pre-exponential factor at a given conversion degree $\alpha_{k}$, and the temperatures $T_{j k}$ are those which the conversion $\alpha_{k}$ is reached at a heating rate $\beta_{j}$. During a series of measurements the heating rate are $\beta=\beta_{1} \ldots \beta_{j} \ldots$

The apparent activation energy was obtained from the slope of the linear plot of $\ln \left(\beta_{j} / T_{j k}^{2}\right)$ vs. $1 / T_{j k}$ performed thanks to a Microsoft ${ }^{\circledR}$ Excel $^{\circledR}$ spreadsheet developed for this purpose.

To apply the method, it is necessary to obtain at least three different heating rates, we work with $\beta=10,20,30 \mathrm{~K} / \mathrm{min}$. Linear plots were computed for $\alpha \in[0.050 .95]$ with a 0.05 step. In the following, Table 1 presents the KAS plots and Fig. 3 shows the results of activation energy vs. conversion degree.

\subsection{Numerical method predicting algorithm}

The prediction of theoretical temperature vs. reaction degree for high heating rates from dynamic scans has a scientific interest for fuels degradation. Indeed, wildfires heating rates can be higher than the classical heating rates of thermal analyser apparatus.

This numerical method allows the calculation of the solid temperature at different conversion degree and outside the experimental range of heating rate authorized by the thermal analyser.
Eq. (6) was rewritten with $b=\left[\ln \left(A\left(\alpha_{k}\right) R / E_{a}\left(\alpha_{k}\right)\right)-\ln g\left(\alpha_{k}\right)\right]$ :

$\ln \left(\frac{\beta_{j}}{T_{j k}^{2}}\right)=-\frac{E_{a}\left(\alpha_{k}\right)}{R T_{j k}}+b$

In order to give the explicit formulas for the solutions to the nonlinear Eq. (7) we use a Mathematica ${ }^{\circledR}$ Package (Wolfram, 2003): "Solve". This function gives the complete set of possible solutions (see Eqs. (8a) and (8b)):

$$
\begin{aligned}
T^{(1)}\left(\alpha_{k}\right) & =-\frac{E_{a}\left(\alpha_{k}\right) / R}{2 W\left(1 / 2 \sqrt{10^{b}\left(E_{a}\left(\alpha_{k}\right)^{2} / R\right) / \beta_{j}}\right)} \\
T^{(2)}\left(\alpha_{k}\right) & =-\frac{E_{a}\left(\alpha_{k}\right) / R}{2 W\left(-1 / 2 \sqrt{10^{b}\left(E_{a}\left(\alpha_{k}\right)^{2} / R\right) / \beta_{j}}\right)}
\end{aligned}
$$

$W$ represents the "product log" function giving the solution for $w$ in $z=w e^{w}$. The function can be viewed as a generalisation of a logarithm. To calculate the temperature for specific cases we select $T^{(1)}\left(\alpha_{k}\right)$. Indeed, $T^{(1)}\left(\alpha_{k}\right)$ gives a real solution and $T^{(2)}\left(\alpha_{k}\right)$ a complex one. The values of $E_{a \alpha}$ and $b$ at different conversion degree are those previously calculated performing KAS method. $T^{(1)}\left(\alpha_{k}\right)$ is then the temperature reached by the solid at a specific conversion degree i.e. specific $E_{a}\left(\alpha_{k}\right)$ and $b$ for the heating rate $\beta_{j}$. In the following section we present results of temperature vs. conversion degree computed from Eq. (8a) at different values of $\beta_{j}$ (i.e. 5, 10, 20, 30, 40, 60, 80 and $100 \mathrm{~K} / \mathrm{min}$ ). Our approach is similar to the one proposed by Vyazovkin [27].

The scope of this study is to provide a global simplified kinetics of the degradation of different wood species with the final aim to be incorporate in a physical fire spread model, that is the reason why we chose to work on dynamic runs and with these high heating rates.

\section{Results}

\subsection{Features of the thermal processes}

For each sample 3 runs were performed with the same experimental conditions, and the reproducibility was verified by good agreement between the 3 obtained mass loss curves (accuracy $\pm 2 \%$ ). Fig. 2 presents the experimental results on thermal degradation of Arbutus Unedo fuel in the range of 400-900 K under air sweeping.

TGA curves of Arbutus Unedo show two steps of weight loss confirmed in DTG by 2 peaks. During the first process the plant is pyrolysed in the temperature range [400-700 K]. Gases emission and oxidation are visualized with a mass loss around $60 \%$.

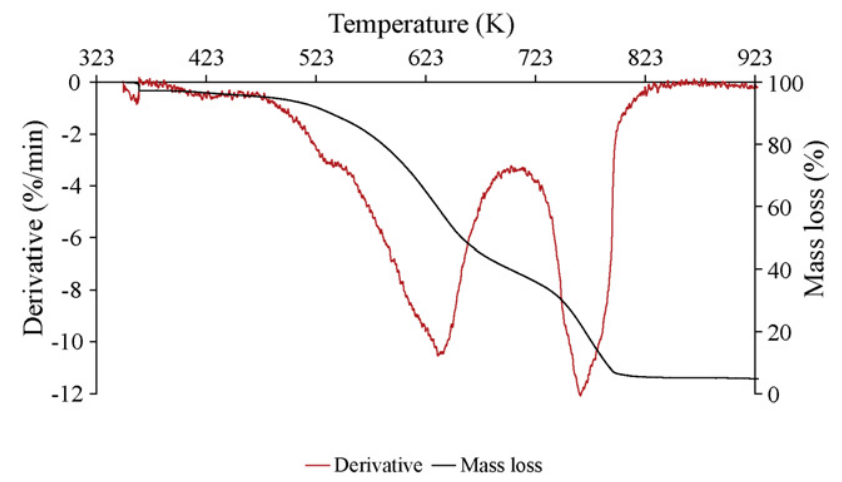

Fig. 2. TGA and DTG curves of Arbutus Unedo obtained with a linear heating rate of $20 \mathrm{~K} / \mathrm{min}$ under air atmosphere. 
The second process can be considered like the surface combustion of charred residue. The char forms ashes in the temperature range [ $700-900 \mathrm{~K}$ ] with a mass loss around $40 \%$ for this step. The same phenomena were observed and recorded by other authors [5,39-41].

\subsection{MFK algorithm}

For the whole degradation $E_{a}(\alpha)$ values were calculated for $\alpha \in\left[\begin{array}{ll}0.05 & 0.95\end{array}\right]$ with a 0.05 step. Table 1 resumes the KAS plots obtained on experiments performed at 10,20 and $30 \mathrm{~K} / \mathrm{min}$. Fig. 3 shows the transformation-degree dependence of the effective activation energy.

To explain the complexity of phenomena we used the approach of Vyazovkin and Lesnikovich [38] based on the inter-relationship between the shape of the curve and the type of process.

In Table 1 , the values of a (indirectly $E_{a}$ ) have a tolerable change, but the vast variation of b due to its large instability is hardly usable. For this reason model-free kinetic approach have the inconvenient to treating the experimental value of $A$ as a dependent and minor parameter [42]. Nevertheless, we chose to use the KAS method in order to get $E_{a}$ for different $\alpha$ and the method proposed herein is dedicated to the simulation of the sample temperature at high heating rates as encountered in wildland fire. We think these results will be useful for fire spread modelling.

As shown in Fig. 3, the dependence has a pronounced increasing character for $0.1<\alpha<0.3$ characteristic of processes involving competing reactions [27]. This fact is in agreement with the phenomena known during the degradation of plants. Indeed, we have seen that two processes occurred in the temperature range from 400 to $700 \mathrm{~K}$ : pyrolysis gases emission and their oxidation. These reactions are competing ones because as gases are produced, they are immediately oxidized by the ambient air. For $0.3<\alpha<0.65$, reactions of pyrolysis and smoldering are in competition. This state involves strong disturbances for the determination of the activation energy. We can see in Table 1 a deviation from the unity for the correlation coefficient in this range of conversion degree. For $0.65<\alpha<0.9$, we noticed an important decreasing dependence of $E_{a}$ in Fig. 3. Vyazovkin and Lesnikovich [38] and Vyazovkin [27] have observed decreasing dependences when studying the thermal degradation of wood and interpreted this fact as the transition of the process to the diffusion regime.

\subsection{Predictions algorithm}

MFK algorithm allowed the calculation of $E_{a \alpha}$ and $b$, for the whole phenomenon at 10,20 and $30 \mathrm{~K} / \mathrm{min}$. Plots of experiments vs.

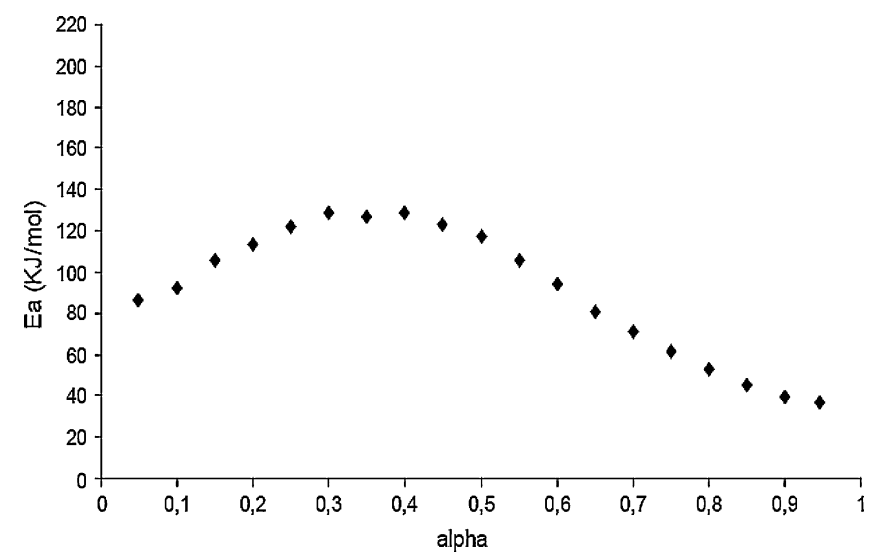

Fig. 3. Transformation-degree dependence of the effective activation energy.

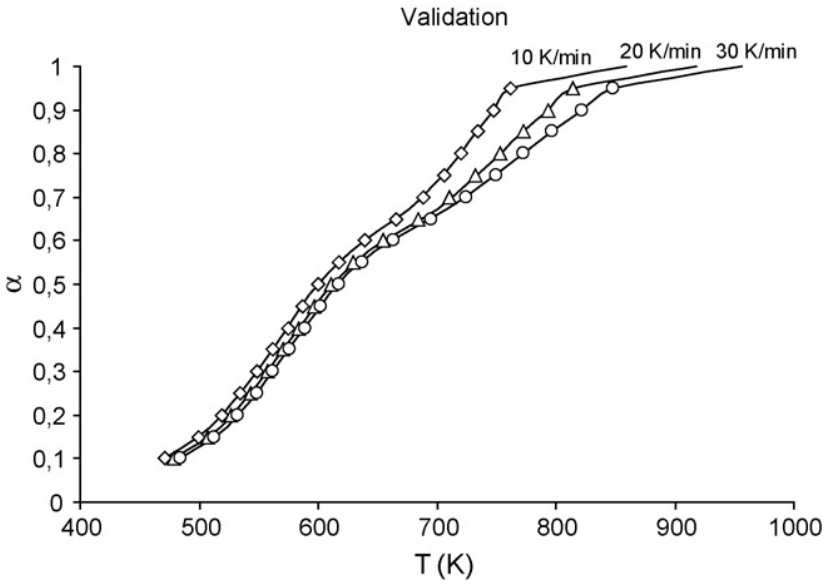

Fig. 4. Experimental (lines) and modelled (symbols) curves of conversion degree vs. temperature at different heating rates.

numerical results (Eq. (6)) are shown in Fig. 4 and a good agreement is observed.

Values of $E_{a \alpha}$ and $b$ (obtained with $\beta=10,20,30 \mathrm{~K} / \mathrm{min}$ ) can be used to fairly describe the dependence of conversion degree on temperature for different heating rates.

The numerical method developed was validated by application to three different heating rates in blind prediction. We selected $5 \mathrm{~K} / \mathrm{min}$ (outside the interval), $25 \mathrm{~K} / \mathrm{min}$ (inside the interval) and $40 \mathrm{~K} / \mathrm{min}$ (limit of the experimental device). The prediction does exhibit a good agreement to experimental data as shown in Fig. 5.

The decomposition of biopolymers in thermogravimetric experiments is a heterogeneous process. Reactions occur at a gas-solid interface, involved certainly a multi-step mechanism for the degradation of this complex sample (several kinetic steps). The derivative of mass loss (Fig. 2) shown two peaks. The first peak has a complex structure, at least two different processes are imposed inside this peak.

The second peak is an individual process confirmed by a better stability of the Ea values. However, we do the choice of a global reaction step because our scope is to provide simplified data for a multi-phasic fire spreading model [22]. Fig. 5 is the proof of the correctness of our considerations.

In wildland fire, the solid sample temperature is a crucial data which is difficult to predict since the heating rate of a particle can vary on a large domain. Fig. 6 is a plot of the sample temperature vs. the conversion degree at different heating rates. Values presented here are numerical ones and come from the calculation of the sam-

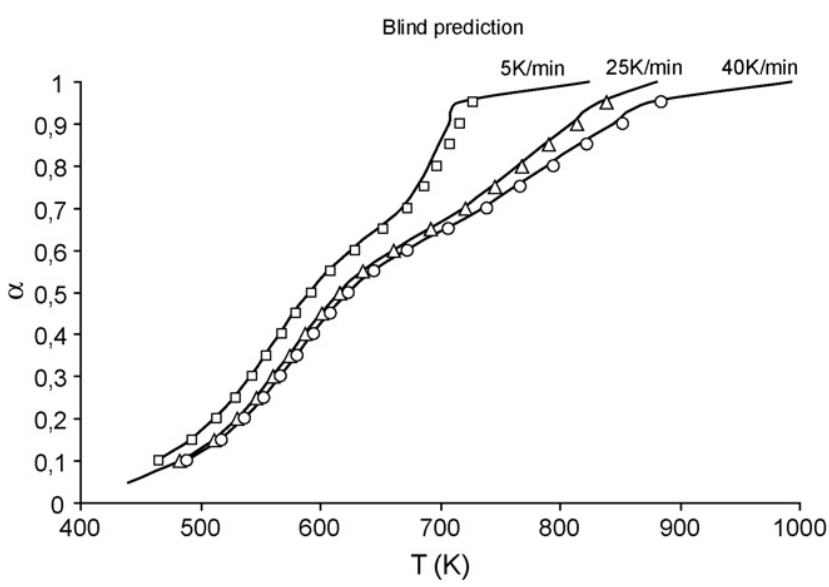

Fig. 5. Experimental (lines) and "blind" simulated (symbols) curves of conversion degree vs. temperature at different heating rates. 


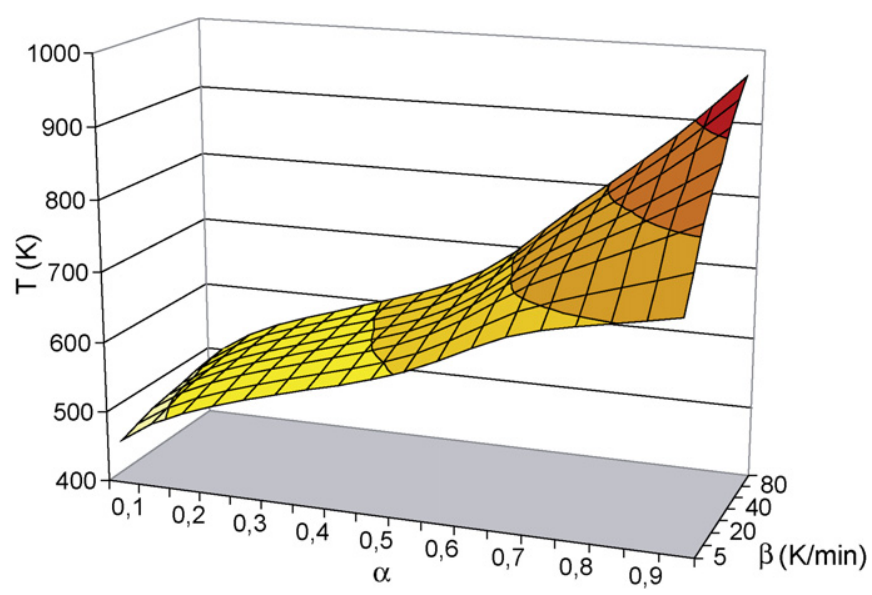

Fig. 6. Surface plot of temperature as a function of extend of conversion degree and heating rates for simulated data.

ple temperature at different conversion degree and heating rates thanks to Eq. (6).

According to the kinetic study two steps were observed: the emission and oxidation of gases in a first time, and the smouldering combustion in a second time. In TGA, these phenomena are a flameless form of combustion and they do have an interest for fire research hazards since frequently, several fire spread are caused by the transition from smouldering to flaming combustion.

The results show that heating rate has a little influence on the reaction temperature for the conversion degree varying from 0.1 to $0.4(462<T<605$ for $5<\beta<100 \mathrm{~K} / \mathrm{min})$. We notice a strong influence of the heating rate on temperature for the values of conversion degree superior to 0.75 . For example at:

$$
\begin{aligned}
& \alpha=0.75, T=680 \mathrm{~K} \text { for } \beta=5 \text { and } T=803 \mathrm{~K} \text { for } \beta=100 \\
& \alpha=0.95, T=715 \mathrm{~K} \text { for } \beta=5 \text { and } T=963 \mathrm{~K} \text { for } \beta=100
\end{aligned}
$$

For values of the conversion degree varying from 0.4 to 0.75 , the heating rate has a moderate influence on the reaction temperature. Thus, high heating rates do have a significant influence on the temperature of the thermal degradation during the smouldering phase. As the heating rate is increasing, the shape of the temperature vs. conversion degree curve is a combination of two linear plots. For the simulation at $\beta=100 \mathrm{~K} / \mathrm{min}$ we found the linear equations:

- $0.1<\alpha<0.45, T=476+329 \alpha$

- $\alpha>0.45, T=259+732 \alpha$

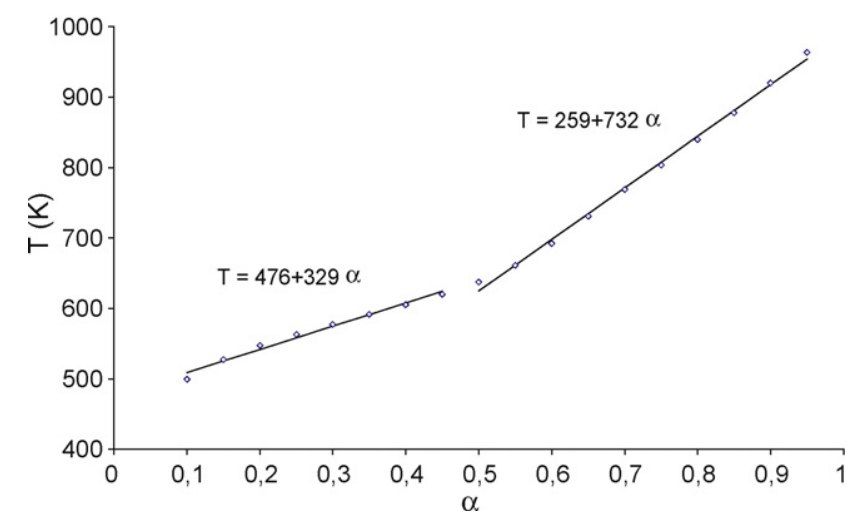

Fig. 7. Simulated plot/linear regression of temperature vs. conversion degree at $\beta=100 \mathrm{~K} / \mathrm{min}$.
The present work demonstrates that at high heating rates, two linear regimes govern the thermal degradation of thin particles. The first step refers to the gases emission and oxidation and the second step concerns the char combustion (smouldering combustion). The transition between those two regimes is easily visualized in Fig. 7 with a strong slope variation of temperature at $\alpha=0.45$ for $\beta=100 \mathrm{~K} / \mathrm{min}$. We present here a way to get a prediction of the solid temperature vs. the conversion degree at high heating rates. This knowledge is important in fire risk quantification since fire spreads are caused by the transition from smouldering to flaming combustion.

\section{Conclusion}

We used TGA in order to study the thermal degradation of a Mediterranean forest fuel. Two stages were visualized under air. The KAS method allowed calculating the activation energy vs. the conversion degree of the thermal degradation under air in the range [400-900 K]. In a first step, the activation energy was calculated for heating rates of 10,20 and $30 \mathrm{~K} / \mathrm{min}$. We found that the activation energy increases from 90 to $125 \mathrm{~kJ} / \mathrm{mol}$ when the conversion degree is varying from 0.1 to 0.4 and the activation energy decreases from 125 to $40 \mathrm{~kJ} / \mathrm{mol}$ when the conversion degree is varying from 0.4 to 0.9 . In a second step, values of activation energy were used to simulate the temperature of the sample for heating rates up to $30 \mathrm{~K} / \mathrm{min}$. As the heating rate increases the results show that the temperature behaviour vs. the conversion degree is affected. At low heating rates, the plot of the temperature exhibits a (sigmoid) shape whereas at high heating rates two linear plots represent the temperature curve. In the field of wildland fire, with high heating rates (around $100 \mathrm{~K} / \mathrm{min}$ ), this work show that the sample temperature is linearly correlated to the conversion degree. With a heating rate of $100 \mathrm{~K} / \mathrm{min}$, the linear plots are: $T=476+329 \alpha$ for $0.1<\alpha<0.45$ and $T=259+732 \alpha$ for $\alpha>0.45$.

\section{References}

[1] E.J. Soltes, in: W.A. Côté (Ed.), Biomass Utilization, Plenum Press, New York, 1983, p. 537.

[2] J.L. Figueiredo, S.S. Alves, in: P.N. Cheremisinoff (Ed.), Thermal Treatment of Hazardous Wastes, Houston, Gulf, 1989, p. 281.

[3] C. Di Blasi, G. Signorelli, C. Di Russo, G. Rea, Ind. Eng. Chem. Res. 38 (1999) 2216-2224.

[4] F. Shafizadeh, in: S.S. Sofer, O.R. Zaborsky (Eds.), Biomass Conversion Processes for Energy and Fuels, Plenum Press, New York, 1981, p. 103.

[5] A.P. Dimitrakopoulos, J. Anal. Appl. Pyrol. 60 (2001) 123-130.

[6] R. Alèn, E. Kuoppala, P.J. Oesch, J. Anal. Appl. Pyrol. 36 (1996) 137-148.

[7] J.H. Balbi, P.A. Santoni, J.L. Dupuy, Int. J. Wildland Fire 9 (1999) 275-284.

[8] S. Liodakis, D. Bakirtzis, A.P. Dimitrakopoulos, Thermochim. Acta 399 (2003) 31-42.

[9] S. Liodakis, D. Vorisis, I.P. Agiovlasitis, Thermochim. Acta 437 (2005) 150-157.

[10] S. Liodakis, T. Kakardakis, S. Tzortzakou, V. Tsapara, Thermochim. Acta 477 (2008) 16-20.

[11] C. Di Blasi, Prog. Energy Combust. Sci. 19 (1993) 71-104.

[12] R.E. Lyon, Polym. Deg. Stabil. 61 (1998) 201-210.

[13] M. Jerguirim, G. Trouvé, Bioresource Technol. 100 (2009) 4026-4031.

[14] S. Liodakis, D. Bakirtzis, A. Dimitrakopoulos, Thermochim. Acta 390 (2002) 83-91.

[15] V. Mamleev, S. Bourbigot, M. Le bras, J. Yvon, J. Lefebvre, Chem. Eng. Sci. 61 (2006) 1276-1292.

[16] S. Yurakul Yorulmaz, A.T. Atimtay, Fuel Process. Technol. 90 (2009) 939-946.

[17] F.C. Beall, H.W. Eickner, USDA Forest Service Research Paper 130, 1970, 2.

[18] D. Cancellieri, E. Leoni, J.L. Rossi, Thermochim. Acta 438 (2005) 41-50.

[19] S. Vyazovkin, N. Sbirazzuoli, Macromol. Rapid Commun. 27 (2006) 1515-1532.

[20] V. Leroy, D. Cancellieri, E. Leoni, Thermochim. Acta 451 (2006) 131-138.

[21] E. Leoni, D. Cancellieri, N. Balbi, P. Tomi, A.F. Bernardini, J. Kaloustian, T. Marcelli, J. Fire Sci. 21 (2003) 117-130.

[22] D. Morvan, J.L. Dupuy, Comb. Flame 138 (2004) 199-210.

[23] N.D. Burrows, Int. J. Wild. Fire 10 (2001) 137.

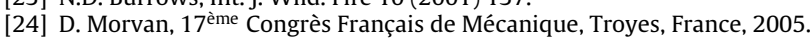

[25] A.K. Galwey, M.E. Brown, Thermochim. Acta 386 (2002) 91-98.

[26] T.P. Prasad, S.B. Kanungo, H.S. Ray, Thermochim. Acta 203 (1992) 503-514.

[27] S. Vyazovkin, Int. J. Chem. Kinet. 28 (1996) 95-101.

[28] S. Vyazovkin, N. Sbirrazzuoli, Macromolecules 29 (1996) 1867-1873.

[29] S. Vyazovkin, C.A. Wight, Int. Rev. Phys. Chem. 17 (1998) 407-433. 
[30] B. Ramajo-Escalera, A. Espina, J.R. Garcia, J.H. Sosa-Arnao, S.A. Nebra, Thermochim. Acta 448 (2) (2006) 111-116.

[31] S. Vyazovkin, C.A. Wight, Thermochim. Acta 340/341 (1999) 53-68.

[32] A. Khawam, D.R. Flanagan, Thermochim. Acta 436 (2005) 101-112.

[33] S. Vyazovkin, C.A. Wight, Annu. Rev. Phys. Chem. 48 (1997) 125-149.

[34] T. Akahira, T. Sunose, Res. Report. CHIBA Inst. Technol. 16 (1971) 22.

[35] T. Ozawa, Thermochim. Acta 355 (2000) 35-42.
[36] J.H. Flynn, L.A. Wall, J. Polym. Sci. B4 (1966) 323-327.

[37] H.E. Kissinger, Anal. Chem. 29 (1957) 1702-1706.

[38] S.V. Vyazovkin, A.I. Lesnikovich, Thermochim. Acta 165 (1990) 273-280.

[39] M.J. Safi, I.M. Mishra, B. Prasad, Thermochim. Acta 412 (2004) 155-162.

[40] C. Branca, C. Di Blasi, J. Anal. Appl. Pyrol. 67 (2003) 207-219.

[41] J. Kaloustian, T.F. El-Moselhy, H. Portugal, Thermochim. Acta 401 (2003) 77-86.

[42] S. Vyazovkin, J. Therm. Anal. Cal. 83 (2006) 45-51. 